\title{
Editorial: Special issue - Austere relations: The changing relationship between the Third Sector, the State and the Market in an era of austerity
}

\author{
Ellen Bennett, Kiri Langmead and Tom Archer* \\ Sheffield Hallam University
}

The relationship between the third sector, the state and the market is in a state of flux. The Coalition, and subsequently the Conservative, administrations' emphasis on austerity continues to play its part in shaping this relationship. As state funding for welfare services is cut and staffing levels are reduced in the name of deficit reduction, third sector organisations (TSOs), including community groups, and voluntary, charitable and other not-for-profit organisation, are increasingly being called upon to fill gaps in welfare provision and meet community needs. Their role and response to this call is shaped by a political ideology that seeks to blend free markets with communitarianism and volunteerism.

In this context, TSOs are facing increasing pressure to reduce their reliance on funding and find instead 'market-based solutions to social problems' (Eikenberry, 2009: 585). This is reflected in current policy changes such as those relating to commissioning and procurement, and methods of impact measurement. In relation to the former, the Localism Act, and related legislations of Community Right to Challenge and Community Right to Bid, seek to offer TSOs the opportunity to compete with private companies to run services and bid on the open market for community assets. Such policies and the rhetoric surrounding them put pressure on TSOs to adopt 'mainstream business practices' (Cameron, 2010, p.1) and engage with the market in its own neoliberal terms (Arvidson et al, 2013; Dayson, 2012). In the current economic, political and ideological context, such policy changes may be understood as a means through which to redefine TSOs' role from mutual aid and community self-help towards a tool of the state and the market.

This special issue is a result of a symposium ${ }^{1}$ arranged by Sheffield Hallam University that brought together researchers and practitioners to consider the extent to which TSOs, in their varying guises, are resisting, realising or challenging the demands and expectations of this rhetoric. The contributions to the symposium, framed by this overarching theme, reflected a broad range of interests and concern including the limitations and potentials of volunteering in the changing climate; TSO responses to changes in economy and policy; and the use of ownership and physical assets for community benefit. The papers in this special issue, consider these themes within contrasting contexts of Community Land Initiatives in the Scottish Highlands, faithbased community action in an English city, and youth volunteering. The diverse range 
p. 101. Editorial: Special issue - The Third Sector, the State and the Market: challenges and opportunities in an era of austerity

of contexts and topics considered within this special issue reflects the sheer scale of the diversity of the 'third sector', and the scale of the challenges facing these organisations in the future.

The complexities of the perceived boundaries between the public, private and third sectors are considered by Braunholz-Speight, in his exploration of Community Land Initiatives (CLIs) in the Scottish Highlands and Islands. Using Gaventa's (2006) Power cube, Braunholz-Speight highlights the interlinking visible, hidden and invisible power relations between public, private and community sectors that come to play through policy, funding initiatives and land ownership transfers. Through this he frames CLIs, not as vehicles of the state or the market, but rather as varyingly engaged with each of these as a response to questions of unequal land ownership. These responses are situated in local cultural understandings of land as a collective resource to be managed at a local level, challenging the disempowering effect of 'closed space' decision-making. In his discussion of power, Braunholz-Speight challenges the notion of a transfer of power from the state to the third sector, and instead considers the re-imagining of the state-sector relationship, illustrated through the emergence of informal, local coalitions that create new relations of power, space and place and emphasise resource sharing as a collaborative and mutual process.

These complex webs of relationships are considered through a different lens in the second paper, as Wier considers the changing relationship between faith-based organisations and the state. In this paper, Wier notes a change in scholarly debates from discussions about the involvement of faith-based organisations in governmentsponsored programmes to discussions about the entrepreneurialism of faith-based groups within broader marketplaces. Wier explores the shifting rhetoric of the church, highlighting the increasingly explicit appeal to the 'entrepreneurial'. Taking three examples of faith-based social action, Wier explores the idea that such activity has grown in the spaces created by the retraction of the state. In doing so, he challenges the suggestion that such action points to the increasing alignment between faith groups and an increasingly neo-liberal agenda.

Dean examines the special issue theme through the context of volunteering. Reflecting back on findings from recent empirical work and positioning these findings within the context of neo-liberal policy, Dean observes a shift in from altruistic to instrumental motivations both amongst volunteers and amongst institutions and organisations that seek to promote volunteering. Dean argues that this shift can be better understood through a critique of the individualisation and marketisation of everyday life that frames volunteers as unpaid workers and a tool for competition, and foregrounds a consumer mind-set and concern for individual benefit. This depicts altruism as an affront to capitalism and undermines the psychological rational for collective, mutual action and care for one and other. As such, Dean concludes that this appropriation of volunteering by the state and markets can undermine the very nature of the third sector, and volunteering.

All of the papers in this special issue, with the exception of MacMillan's, were drafted prior to the UK's 2015 general election. A different result may have impacted on the salience of these papers for the new government's agenda. However, with a new Conservative administration showing little sign of radically altering or reversing its policy toward the third sector, these papers are even more pertinent now than when they were when they were originally drafted. We believe that they highlight emerging challenges and opportunities for those working in the sector, and those making policy for its future development. 
p. 102. Editorial: Special issue - The Third Sector, the State and the Market: challenges and opportunities in an era of austerity

McMillan's paper offers a hopeful and timely conclusion to this special edition, as it did to the 2015 symposium. Following a description of conventional wisdom in third sector research and dominant narratives of 'necessity and transformation' and 'jeopardy and loss', McMillan encourages us, as researchers and practitioners, to adopt a different narrative. The purpose of this transition is to escape the purported inevitability of processes of marketization, understood as an exogenous force that acts on passive TSOs and restricts space for plural and autonomous action, and to move away from an understanding of TSOs as bounded entities. Rather, McMillan suggests positioning TSOs within a complex, dynamic and intersubjective field. He argues that taking this view has the potential to shift focus from organisations themselves to the meeting points of fields, as sites of action and struggle. In these sites, TSOs may be reimagined as actors constructing and shaping markets to their advantage, reclaiming the agency of both TSOs and TS research.

To conclude, we would like to thank everyone that was involved in the symposium, both organisers and attendees, for prompting such a breadth of interest and debate. We would also like to thank all those that have contributed to this special issue, especially the authors, reviewers and editorial assistants.

\section{Notes}

1 An account of the symposium was developed using Storify.com. This can be accessed here.

* Correspondence Address: Ellen Bennett, Kiri Langmead and Tom Archer, CRESR, Sheffield Hallam University, Unit 10, Science Park, Howard Street, Sheffield, S1 1WB. Email: ppp-online@shu.ac.uk 